\title{
A study on impact of an affiliate marketing in e-business for consumers' perspective
}

\author{
Suresh $\mathrm{V}^{\# 1}$, Vetri Selvi $\mathrm{M}^{* 2}$, Maran $\mathrm{K}^{\# 3}$ A.R.Shanmuga Priya ${ }^{\# 4}$ \\ ${ }^{1}$ Faculty of Management, SRM Institute of Science and Technology, Chennai, India \\ ${ }^{2}$ HOD-School of skill building, SRM University, Sikkim \\ ${ }^{3}$ Sri Sairam Institute of Management Studies,Sri Sairam Engineering College, Tambaram \\ ${ }^{4}$ Faculty of Management, SRM Institute of Science and Technology, Chennai, India \\ ${ }^{1}$ vsureshmba81@gmail.com, suresh.v@ktr.srmuniv.ac.in, \\ 22vetriselvi.m@srmus.ac.in, ${ }^{3}$ maran.mba65@gmail.com, ${ }^{4}$ sasesha2003@gmail.com
}

\begin{abstract}
Affiliated marketing is a type of online marketing technique where a publisher promotes a business through an advertisement on their web site and that leads to business rewards the affiliate with commission each time a visitor, customer generates sales. Affiliate marketing defined as performance marketing and associate marketing. Affiliate marketing integrates with 3 parties:-Advertiser, Publisher, and Consumer. Advertisers can be selling of any companies products like electronics, books, clothing, and air tickets online or could be insurance company selling policies etc. Publisher means who promotes advertiser's products or services through its website or blog. Consumer is the king and very prominent to part of this cycle who attract the advertisement and then makes an action (click) from publisher's website to advertiser's website and after purchased a product that is called conversion. This article find out the inner workings of affiliate marketing. It defines the affiliate marketing marketplace including some of the participants and explores the characteristics of a successful long-term win-win relationship. Affiliate marketing is mainly used to mainstream marketing strategy for e-commerce businesses in the future. A mixed method approach was adopted to analyse the consumers' perspective, via an online questionnaire. The results of the overall rating of product price, quality $\&$ time of trend to buy and promote the product in a easy way to reach customers in the online itself.
\end{abstract}

Keywords: e-commerce, affiliate marketing and consumers’ perspective

\section{INTRODUCTION}

A digital marketing is a place for buyers and sellers are interacting and online retailer pay commission to an external website for generating sales or traffic through its referrals. The affiliated marketing overlaps with internet marketing methods to some degree, because of affiliates use regular advertising methods. Those methods use effective search engine optimization (SEO), paid search engine marketing (PPC - Pay Per Click), content marketing, e-mail marketing and in some sense display advertising. Additionally the affiliated marketing sometimes use conservative techniques of publishing reviews of products or services offered by a partner. The supplier in e-commerce as short for business-to-business in electronic commerce, that is selling products or services between businesses through the internet via an online sales portal. Generally, it is mainly used to improve the efficiency to sales of the products or services for companies. The traditional method is processing orders manually - by telephone or e-mail but e-commerce orders can be processed digitally. The customer of e-commerce with facilitate of digital marketing as a new emerging trend to buy a good/products in the e-commerce website through the affiliate network or with the direct online e-commerce websites. It was direct connection between merchant (online e-commerce retailer) and customer(end user) which had a low level relationship now. When the customers to buy a product/services from online merchants confuses about each and every product dimensions of quality, price, delivery are different from other competitors. It establishes a time saving method for both merchant and customer through the affiliate link(Social media blogs).

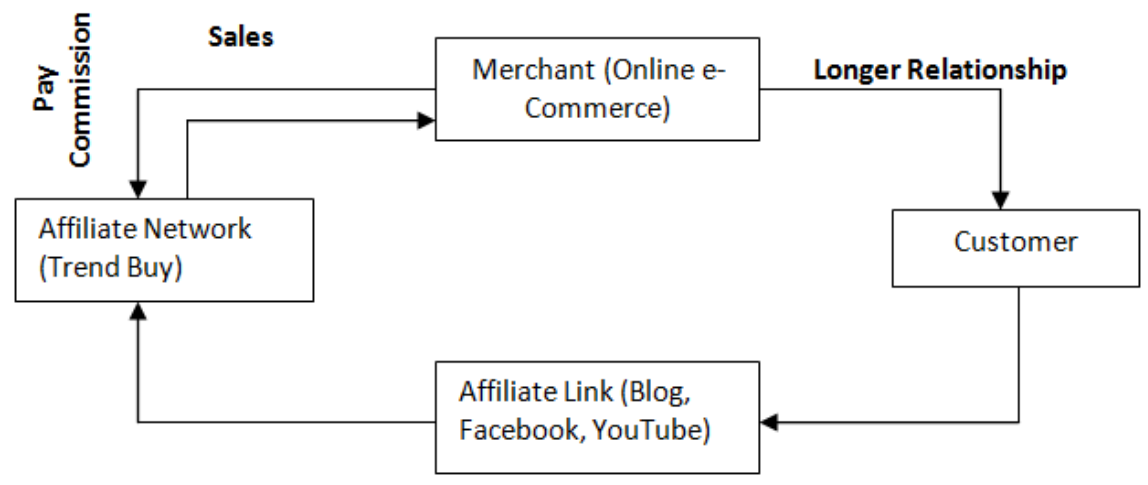

Fig. 1 Framework of Affiliate Marketing of Consumers’ Perspective for E-Busines 
]Merchant:

A merchant(online e-commerce) who sell the product in digital marketing. They provide the offers, a discount, and gift voucher to impress customer on promotional strategy to buy a product. In addition to maintain the long term relationship with customer in a continuous process to improve their sales force.

Affiliate network:

The affiliate network create a link or website to maintain a connection between the merchants and customers to make commission for the affiliate who work as a intermediate with help of social media sites like blog, facebook, youtube etc. The affiliate marketing makes an easy transaction for the customer in buying a product through the affiliate network(Trend buy).

Affiliate link:

An affiliate link is a specific Uniform Resource Locator (URL) that contains the affiliate's ID or username. In affiliate programs, advertisers use affiliate links to record the traffic and that sent to the advertiser's website. The affiliate marketing is responsible for arranging its own affiliate link and connects to the advertiser's website with use of social media blogs(face book, youtube, etc)

Customer:

The customers to buy the product in e-commerce site scare about particular product because of duplicate, damage and shipment of e-commerce. Affiliate network expert see the offer ,rating ,review ,price comparison, originality and benefit of the product and create link through share social media like blogs. The customers click this link to buy the particular product. The affiliate network marketing is more benefits to the merchant to maintain the long term relationship with customer for increase the sales forces.

\section{LITERATURE REVIEW}

Gerald L. Lohse Steven Bellman Eric J. Johnson (2000)Stated that Online retailing is a big business from the late 1998 to till now, so millions of people have ordered holiday gifts in the online and retailers has increased to upgrade their distribution of networks to increase the growth of retail marketing.[1]

Chaffey et al. (2003) Stated the internet marketing strategy as "the definition of approach by which the internet marketing will support the marketing and business objectives of the organizations." This study analyze in several marketing researchers believe that the companies do not require a separate internet marketing strategy.[2]

Evanschitzky, H., \& Iyer, G. R. (2007) Companies has plan for the growth of online shopping, and online consumers' purchasing behaviour are required to the companies for define their online retail strategies for inventory holding, distribution, product variety, market segmentation, online advertising and web site design. Forecasts could be reliable based on online consumers' purchasing behaviour.[3]

kotler and armstrong (2008) Defined that there are four major online marketing domains: (i) business-toconsumer (b2c), (ii) business-to-business (b2b) ,(iii) Consumer-to-Consumer (c2c), (iv) Consumer-to-Business (c2b)[4].

Chaffey (2009) Stated the affiliate marketing is a commission based arrangement where the merchant pays a percentage or a fixed commission to the referring website (affiliate publisher) for each lead or sale delivered.[5]

Karim, M. R. (2012). Reported that time spent in online buyers has been continuously increased year by year. The online spending has increased to \$ 12.1 billion and online buyers has increased 49.6 million in 2015 and online spending has $\$ 22.7$ billion and online buyers has 67.5 million in 2016. The online spending will be reached \$ 74.7 billion and online buyers will be increased 167.8 million in 2020.(6)

zia ul haq (2012) Narrated the online advertising lead for direct marketers, It is used as a source of information, this study findings of survey was a positive view of affiliate marketing. Consumer attitude of affiliate marketing is the usefulness, informativeness, incentive and trust[7].

Benjamin Edelman (2015) Mentioned that some merchants hire outside specialists, In house staff are more successful at identifying and excluding affiliates and this study considered the implications for online marketing of affiliate programs more generally[8].

Dr. Sonal Kala \& Rajesh Kumar Sharma (2015), Stated that Internet is the central-hub for quick and rapid lifestyle, communication, connecting with people for official purposes. The interactions between customers and service providers in electronic commerce through the retailer's website. This study measured the relationship between various characteristics of online shopping and customer purchase behaviour towards online shopping and future of online shopping in India. [9]

Obaidat, M. S., \& Lorenz, P. (2016) Short form of electronic commerce is e-commerce, it is a type of innovative business model where individual or group or a firm can buy and sell on electronic network with support of internet. The another names of e-commerce are online commerce, web commerce, e-retail, e-tail and e-comm. But e-tail refers to any transactional processes around retail.[10] 
Global Trends in Online Shopping - Nielsen Reports(2017) that published the overall online shopping trends in the late 2000. Totally, over 875 million consumers have shopped in the online. The number of online shoppers has also increased up to $40 \%$ in the last two years from 2006 to 2008.[11]

\section{OBJECTIVE OF RESEARCH}

To analyze the consumer preferences through price comparison/discount/offers in online marketing.

\section{RESEARCH METHODOLOGY}

This study adopts exploratory research to identify the consumer preferences through price comparison/discount/offers in online marketing. The study consists of 89 respondents (online buyers) in Chennai. To analyse the data, convenience sampling method is adopted and the Independent sample test is used as a data analysis tool in this study.

\section{DATA ANALYSIS AND INTERPRETATIONS}

The one-way analysis of variance (ANOVA) is used to determine whether it has any statistical significant differences between the means of two or more independent (unrelated) groups (three rather than two groups).

Table I: ANOVA Table for Consumers’ Preferences of Affiliate Marketing:

\begin{tabular}{|c|c|}
\hline ALPHA( $(\boldsymbol{\alpha})$ & VALUE \\
\hline 0.10 & 1.67 \\
\hline 0.05 & 1.96 \\
\hline 0.02 & 2.33 \\
\hline 0.01 & 2.54 \\
\hline
\end{tabular}

This study use a one-way ANOVA to understand whether the consumer preferences are different through price comparison/discount/offers in online marketing. The consumers are dividing into three independent groups (e.g., low, medium and high-stressed students).

PRICE:

$\mathrm{H}_{\mathrm{O}}$ : - Price of the product will have no significant effect on age of the respondent.

$\mathrm{H}_{1}$ : - Price of the product will have significant effect on age of the respondent

Table No 2: ANOVA table for consumers’ preferences of price to affiliate marketing:

\begin{tabular}{|l|c|c|c|c|c|}
\hline ANOVA & Sum of Squares & df & Mean Square & F & Sig. \\
\hline Between Groups & .790 & 2 & .395 & .498 & .609 \\
Within Groups & 69.032 & 87 & .793 & & \\
Total & 69.822 & 89 & & & \\
\hline
\end{tabular}

The sum of square is 69.032, degree of freedom is 87 , mean square value is 0.793 in with in the group, sum of square is .790, degree of freedom is 2, mean square value is 0.395 in between groups and $\mathrm{F}$ value is a 0.498 . Then significance value is 0.609 . Hence the calculated value(0.609) is less than tabulated value(1.96). So finally Ho is accepted, i.e there is no significance differences of price of the product to age of the respondent.

Quality:

$\mathrm{H}_{\mathrm{O}}$ : - Quality of the product will have no significant effect on age of the respondent.

$\mathrm{H}_{1}$ : - Quality of the product will have significant effect on age of the respondent

Table No 3: ANOVA table for consumers’ preferences of quality to affiliate marketing:

\begin{tabular}{|l|c|c|c|c|c|}
\hline ANOVA & Sum of Squares & df & Mean Square & F & Sig. \\
\hline Between Groups & 5.740 & 2 & 2.870 & 2.906 & 0.060 \\
Within Groups & 85.916 & 87 & .988 & & \\
Total & 91.656 & 89 & & & \\
\hline
\end{tabular}


The sum of square is 85.916, degree of freedom is 87, mean square value is 0.988 in with in the group, sum of square is 5.740 , degree of freedom is 2 , mean square value is 2.870 in between groups and $\mathrm{F}$ value is a 2.906 . Then significance value is 0.060 Hence the calculated value(0.060) is less than tabulated value(1.96) so finally Ho is accepted, i.e there is no significance differences of quality of the product to age of the respondent

\section{TIME OF DELIVERY:}

$\mathrm{H}_{\mathrm{O}}$ : - Time of delivery of the product will have no significant effect on age of the respondent.

$\mathrm{H}_{1}$ : - Time of delivery of the product will have significant effect on age of the respondent.

Table No 4: ANOVA table for consumers' preferences of time of delivery to affiliate marketing:

\begin{tabular}{|l|c|c|c|c|c|}
\hline ANOVA & Sum of Squares & df & Mean Square & F & Sig. \\
\hline Between Groups & 3.919 & 2 & 1.959 & 3.095 & 0.050 \\
Within Groups & 55.070 & 87 & .633 & & \\
Total & 58.989 & 89 & & & \\
\hline
\end{tabular}

The sum of square is 55.070 , degree of freedom is 87 , mean square value is 0.633 in with in the group, sum of square is 3.919 , degree of freedom is 2, mean square value is 1.959 in between groups and $\mathrm{F}$ value is a 3.095 . Then significance value is 0.050 . Hence the calculated value(0.050) is less than tabulated value(1.96) so finally Ho is accepted, i.e there is no significance differences of time of delivery of the product to age of the respondent.

\section{CONCLUSION:}

Affiliate marketing is a new way of advertising method and third parties(referral channel) to promote another company's product or service and credit a commission for any sales generated. Affiliate marketing is a major revenue driver for ecommerce stores and translating customers visibility into brand awareness and sales. It is a revenue share because of customers' relevant visit and the highly-qualified traffic lead to online businesses. Affiliate marketing is a successful method because of cultivating an audience and developing a good relationship with customers. Affiliate marketing is excel at driving traffic for informational search queries about a product or brand or industry. Affiliates marketing drive is mainly used to attract the new visitors to website via new users from traffic and paid traffic, the third party earn by providing engaging content and developing a harmonious relationship with their customers. Affiliates marketing earn the trust of their customers and can act as a type of middleman or brand advocate for an online business. Affiliate marketing integrates with 3 parties:Advertiser, Publisher, and Consumer. Advertisers can be selling of any companies products like electronics, books, clothing, and air tickets online or could be insurance company selling policies etc. Publisher means who promotes advertiser's products or services through its website or blog. Consumer is the king and very prominent to part of this cycle who attract the advertisement and then makes an action (click) from publisher's website to advertiser's website and after purchased a product that is called conversion. The results of the overall rating of product price, quality \& time of trend to buy and promote the product in a easy way to reach customers in the online itself.

\section{REFERENCE}

[1] Azeem, Abdul; ul Haq, Zia. Global Business and Management Research; Boca Raton Vol. 4, Iss. 1, (2012): 28

[2] Ben Edelman, Wesley Brandi, Information and Incentives in online affiliate marketing, March 2014.

[3] C.A.Janeway, P.Travers, M.Walport,Introduction to online marketing, March 2014.

[4] Diana Luck, Geoff Lancaster, (2003) "E-CRM: customer relationship marketing in the hotel industry", Managerial Auditing Journal, Vol. 18 Issue: 3, pp.213-231, https://doi.org/10.1108/02686900310469961

[5] Evanschitzky, H., \& Iyer, G. R. (2007). E-Services: Opportunities and Threats - Journal of Value Chain Management, Vol. 1, No. 1/2 (Special Issue). Springer Science \& Business Media.

[6] Franz-Rudolf Esch, Kristina Strödter(2008) online marketing,DOI: 10.1002/9781405186407.wbiecm009

[7] Global Trends in Online Shopping - A Nielsen Report, http://www.nielsen.com/us/en/insights/reports/2010/Global-Trends-in-OnlineShopping-Nielsen-Consumer-Report.html

[8] https://books.google.co.in/books

[9] Kala, S., \& Sharma, R. K. (2015). Behavior of customers towards online shopping in India. International Journal of Core Engineering and Management, 2(4), 127-131.

[10] Lohse, G. L., Bellman, S., \& Johnson, E. J. (2000). Consumer buying behavior on the Internet: Findings from panel data. Journal of interactive Marketing, 14(1), 15-29.

[11] Jaime Diaz, Cristian Rusu, Experimental validation of a set of cultural-oriented usability heuristics: e-commerce websites evaluation, volume 50, February 2017

[12] Maria del Mar Roldan Garcia, Jose Garcia-Nieto, An ontology-based data integration approach for web analytics in e-commerce, November 2016.

[13] Obaidat, M. S., \& Lorenz, P. (2016). E-Business and Telecommunications: 12th International Joint Conference, ICETE 2015, Colmar, France, July 20-22, 2015, Revised Selected Papers. Springer. 
[14] P.K.Kannan, Hongshuang, Digital marketing: A framework, review and research agenda, Volume34, Issue1, March 2017.

[15] Tiago Oliveria, MatildeAlhinho, Modelling and testing consumer trust dimensions in e-commerce, June 2017.

[16] Williams Ezinwa Nwagwu, Bunmi Famiyesin, (2016) "Acceptance of mobile advertising by consumers in public service institutions in Lagos, Nigeria", The Electronic Library, Vol. 34 Issue: 2, pp.265-288, https://doi.org/10.1108/EL-09-2014-0169

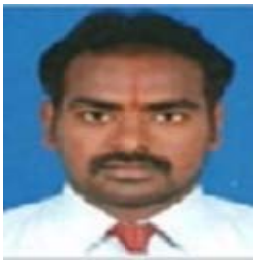

\section{AUTHOR PROFILE}

Suresh V submitted a Doctorate of Philosophy on the topic of "Impact of online purchasing of branded laptops and customers satisfaction with reference to Chennai city” at Bharathiar University in India and he is a Master of Philosophy(M.Phil) in Management studies from Vinayaka Missions University and a post graduate in Master of Business Administration(MBA) from ANNA University, qualified in UGC-NET and a post graduate in Master of Astrology. He is also a certified Teachers on - Total Quality Management Course from SRM University. He is in the field of teaching post graduate students of Management for 13years and subject matter expert in the areas of Marketing, E-commerce Managerial Statistics, Production Management, Operations Management and Operations Research. He received Ist Prize in Sarvodaya(Soap) Sales Programme at PG echelon. He Participated in POEM WRITING competition "Velga Baratham” at Bharathiar University at UG level. He received the best faculty award from a private top engineering college. He has presented papers in several National and International Conference and He has around 18 publications to his credit. Also 8 publications in SCOPUS indexed journals, 2 ABDC JOURNALS, 4 UGC listed journal and another 4 accepted for publication in the SCOPUS indexed Journals.

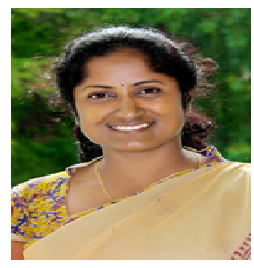

Ms. Vetri Selvi. M is a Master of Philosophy (M.Phil) in Management from Periyar University, and a post graduate in Master of Business Administration (MBA) from University of Madras. She is an Engineering graduate from Bharathiyar University and holds two Master degree in Yoga. She is awarded as a LEAN SIX SIGMA GREEN BELT by Benchmark six sigma and certified in Project Management from PMI. She is also awarded as a HR facilitator from CLHRD. She is in the field of teaching post graduate students of Management for 12 years and Engineering graduates for 20 years. She is a subject matter expert in the areas of Quality Management, Production and Operations Management and Logistics and Supply chain Management. She has an Industrial experience of 6 years as a Project Engineer. She has attended more than 50 National and International conferences, seminars, workshops and Faculty Development Programs and presented papers. She has 7 publications to her credit in SCOPUS indexed journals, UGC listed journal and reputed Journals. 